\title{
ВЛИЯНИЕ ОСТАТОЧНЫХ НАПРЯЖЕНИЙ В ЗОНАХ СВАРНОГО УЗЛА НА СОПРОТИВЛЕНИЕ ХРУПКИМ РАЗРУШЕНИЯМ
}

\author{
Заворин Александр Сергеевич',
} zavorin@tpu.ru

Любимова Людмила Леонидовна', II@tpu.ru

Буваков Константин Владимирович', buvakov@tpu.ru

\author{
Кулеш Айгуль Сабировна', \\ ronikul@tpu.ru
}

Ташлыков Александр Анатольевич', tashlykov@tpu.ru

\author{
Кулеш Роман Николаевич', \\ ronikul@tpu.ru \\ 1 Национальный исследовательский Томский политехнический университет, \\ Россия, 634050, г. Томск, пр. Ленина, 30.
}

\begin{abstract}
Актуальность исследования в области прочности и разрушения сварных узлов связана с необходимостью обеспечения высокой надежности и безопасности эксплуатации опасных производственных объектов. В настоящее время признана роль внутренних напряжений и их релаксации как самостоятельной причины разрушения. Конечной формой предельного состояния является появление трещин, однако признаки наступления предельного состояния узла или конструкции не сформулированы. Цель исследования: установление признаков предразрушения и разрушения зон сварного шва по условиям перераспределения внутренних напряжений при термической релаксации.

Объект: сварные узлы пароперегревателя, выполненные из разнородных сталей.

Методы: физическое моделирование условий эксплуатации путем термоциклирования образцов в электропечи МИМП-10УЭ, рентгенометрия образцов, оценка внутренних структурных напряжений на рентгеновских дифрактометрах типа ДРОН, морфологический анализ с применением металлографического анализатора «Ресурс С7», включающего инвертированный микроскоп Olympus GF41 с программным обеспечением SIAMS Photolab, морфология трещин с помощью микроанализатора типа PEN SCKOPE, анализ микротвердости при использовании микротвердомера ПМТ-3.

Результаты. На основании гипотезы о корреляции трещинообразования с процессами релаксации внутренних напряжений показано, что появление и рост трещины и релаксация напряжений являются взаимосвязанными процессами. В результате термофлуктуационных релаксаций обнаружены одни и те же качественные закономерности для однофазной и двухфазной системы фаз, приводящие к разрушению. Для образца с начальной трещиной в условиях отсутствия внешних нагрузок и деформаций протекающие в образце процессы естественного старения контролируются только внутренними напряжениями, которые приводят в действие все механизмы разрушения, в том числе и фазовый распад. По условиям термофлуктуационной релаксации внутренних напряжений устанавливается температурная граница области напряженных состояний, определяющая надежную эксплуатационную температуру.
\end{abstract}

\section{Ключевые слова:}

Сварной узел, околошовная зона, зона термического влияния сварки, внутренние напряжения, термоциклирование, термическая релаксация, микротвердость, трещинообразование.

\section{Введение}

Наиболее ответственными и опасными узлами элементов теплоэнергетического оборудования являются сварные узлы [1-6]. Это в особенности относится к тем узлам, при изготовлении которых используются материалы, разнородные по своим механическим, химическим, прочностным и теплофизическим характеристикам. Неоднородность свойств металла шва, околошовной зоны (ОШЗ), зоны термического влияния (ЗТВ) и основного металла, температурные градиенты и фазовая перекристаллизация как результат сварочного процесса являются причиной возникновения оста- точных напряжений в сварном узле и сильнейшим фактором, определяющим его сопротивление усталости [7-13].

В процессе проектирования производится детальный анализ основных режимов работы конструкции [14-16]. Тем не менее это не является достаточной гарантией работоспособности узла или конструкции [11, 17]. Как правило, внутренние напряжения имеют весьма сложный характер распределения, поэтому влияние остаточных напряжений на сопротивление усталости для различных участков зоны сварного узла, околошовной зоны или зоны термического влияния сварки будет раз- 
личным [17-21]. Кроме этого, внутренние напряжения при наличии градиентов температур и внешних нагрузок имеют свойство не прогнозируемо перераспределяться и подвержены неоднородным релаксациям. При этом они могут достигать значительных величин, превышающих предел текучести исходного материала $[19,20]$. Роль остаточных напряжений существенно увеличивается с ростом концентрации напряжений и в этих случаях они могут изменять предел выносливости в несколько раз как в сторону увеличения, так и уменьшения [22, 23]. Долговечность сварных соединений при этом изменяется в десятки раз. Это обстоятельство затрудняет использование расчетных методов для количественных оценок [17, 24].

Обычно при оценках остаточного ресурса опираются на вероятностные методы, основанные на статистике отказов; применяют комплексные подходы, базирующиеся на результатах разрушающего и неразрушающего контроля и поверочных расчетах на прочность. Эти подходы обнаруживают свои недостатки - отсутствует строго установленный порядок применения средства контроля, последовательности, периодичности, объема контроля. В наиболее ответственных отраслях промышленности, например, в атомной и тепловой энергетике, такие инструкции имеются, но даже в этих отраслях существует проблема определения предельного состояния металла $[17,25]$. Главный недостаток существующих методик заключается в том, что они в основном предполагают низкие значения допустимых напряжений $\sigma_{\text {доп }}$ Обычно, $\sigma_{\text {доп }} \leq \sigma_{0,2} / 2$, а для ответственных конструкций $\sigma_{\text {доп }} \leq 0,3 \sigma_{0,2}\left(\sigma_{0,2}-\right.$ условный предел текучести металла).

В то же время фактические значения внутренних напряжений могут как достигать предела текучести, так и превышать его [17-20, 22, 26].

Конечной формой предельного состояния является появление трещин, однако признаки возможности наступления предельного состояния узла или конструкции не сформулированы.

Роль внутренних напряжений в процессах разрушения очевидна, и причиной нарушения работоспособности может быть недостаточность имеющихся представлений о возможных неблагоприятных ситуациях, возникающих при эксплуатации за счет перераспределении полей действующих остаточных напряжений.

Эти обстоятельства определили иель настоящей работы - установление признаков предразрушения и разрушения зоны сварного шва по условиям перераспределения внутренних напряжений при термической релаксации.

Объектол исследований являлись образцы сварных узлов из разнородных сталей. Исследованиям подвергались образцы из зоны шва, ОШЗ и 3ТВ, представляющие собой однофазные и двухфазные структуры, состоящие из $\alpha, \gamma$ и $(\alpha+\gamma)-$ фаз железа. Это требует необходимости установления отдельных для каждой фазы или общих признаков потери металлом способности сопротивляться разрушению.

Работа выполнялась в два этапа.

1. В первой части представлены результаты исследования перераспределения системы напряженных состояний в зонах сварного шва, разрушенного в процессе организованного термоциклирования (образцы 1-5, рис. 1). Сварной узел выполнен из разнородных сталей - перлитной жаропрочной низколегированной стали $12 \mathrm{X} 1 \mathrm{MФ} \mathrm{и} \mathrm{распространенной} \mathrm{аустенитной} \mathrm{хро-}$ моникелевой стали $12 \mathrm{X} 18 \mathrm{H} 9 \mathrm{~T}$.

2. Вторая часть работы является тестовой для первой, так как представляет исследование системы напряженных состояний в зонах сварного шва с начальной (сварочной) трещиной (образцы 7-13, рис. 10). Сварной узел с трещиной выполнен из разнородных сталей - перлитной жаропрочной низколегированной стали $12 \mathrm{X} 1 \mathrm{M \Phi}$ и аустенитной хромо-марганцевой стали Ди-59 (10Х13Г12С2Н2Д2Б), созданной на замену хромоникелевых сталей Х18H (9-10) T.

Методика исследований. 1. В первой части работы термоциклирование осуществлялось в атмосфере воздуха в диапазоне температур от 100 до $1000{ }^{\circ} \mathrm{C}$ с шагом повышения температуры $100{ }^{\circ} \mathrm{C}$ в каждом очередном цикле нагрева. Выдержка образцов в печи в стационарном режиме составляла 1,5 ч. Охлаждение образца производилось с печью.

Зональные напряжения $\sigma_{I}$ определялись для каждого цикла нагрева на основе данных о значениях параметров элементарных ячеек в соответствии с законом Гука по выражению:

$$
\sigma_{I}=\frac{\Delta a}{a} E=\frac{a_{0}-a_{i}}{a_{0}} E,
$$

где $a_{i}, a_{0}$ - соответственно текущее значение параметра элементарной ячейки и значение параметра элементарной ячейки эталона, $\AA ; E$ - модуль нормальной упругости, МПа.

Параметр кристаллической кубической решётки для $\alpha$-фазы рассчитывался по дифракционному рефлексу (110), а для $\gamma$-фазы - по дифракционной линии (111) в соответствии с выражением:

$$
a=d \sqrt{H^{2}+K^{2}+L^{2}}=\frac{\lambda}{2 \sin \theta} \sqrt{H^{2}+K^{2}+L^{2}},
$$

где $d$ - межплоскостное расстояние; $H, K, L$ - индексы Миллера дифракционной линии; $\theta$ - угол дифракции; $\lambda$ - длина волны, $\AA$.

Рентгеносъемка проводилась на рентгеновском аппарате ДРОН-3 в прецизионном режиме при скорости вращения детектора 1/8 град/мин; угол сканирования составлял 0,02 град. В работе использовалось монохроматическое излучение от медного антикатода с кварцевым кристаллом-монохроматором; при этом длина волны излучения составляла $\lambda_{\mathrm{CuK}_{\beta}}=1,39217 \AA$.

3. Вторая часть работы включала вырезку и подготовку образцов из всех критических зон сварного узла с начальной сварочной трещиной, 
рентгенофазовый анализ образцов, микротвердометрию, микроструктурный анализ и измерение внутренних зональных напряжений. Рентгеносъемка проводилась на рентгеновском аппарате ДРОН-2,0 с использованием селективно-поглощающего никелевого $\beta$-фильтра для $\mathrm{CuK}_{\alpha}$ - излучения при скорости вращения детектора 1/2 град/мин; угол сканирования составлял 0,1 град. Длина волны излучения рентгеновской трубки равна $\lambda_{\text {сuK }_{\alpha c}}=1,54178 \AA$.

Техника эксперимента. Для установления характера распределения внутренних структурных напряжений применялся метод рентгеноструктурного анализа с использованием рентгеновских дифрактометров общего назначения типа ДРОН. Для морфологического анализа структурных составляющих стали и оценки качества поверхности применялся металлографический анализатор «Ресурс C7», включающий в себя инвертированный микроскоп Olympus GF41 с программным обеспечением SIAMS Photolab (относительная погрешность измерений от $\pm 0,25 \%$ при увеличении до 500 включительно и до $\pm 0,65 \%$ при увеличении свыше 500). Морфология поверхности при трещинообразовании диагностировалась микроанализатором типа PEN SCKOPE с увеличением до 100 (и 200) включительно. Микротвёрдость анализировалась при помощи микротвердомера ПМТ-3 по методу Виккерса. Термоциклирование осуществлялось в электропечи МИМП-10УЭ.

\section{Исследование системы напряженных состояний в зонах сварного шва, разрушенного термоциклированием}

На рис. 1 представлена схема вырезки образцов № 1-5 для исследований.

\section{Экспериментальные результаты исследований \\ распределения напряжений в ОШЗ и ЗТВ \\ в образцах 1, 2 из стали 12Х1МФ}

Образцы № 1 и 2 рентгенографически представляют собой однофазную систему фаз в виде $\alpha$-фазы железа. Циклический отжиг сопровождается осцилляцией зональных напряжений от растягивающих до сжимающих, от упрочнения до разупрочнения (рис. 2, 3).

Такое поведение частично соответствует теоретическим представлениям о поведении гипотетических сред - вязко-упругой среды Максвелла, когда наблюдается релаксация напряжений до нуля, или среды Кельвина, когда напряжение при релаксации приближается к некоторому постоянному значению [27-30]. Отличие реальных сред от гипотетических сводится к тому, что в реальном материале при определенных условиях могут реализовываться обе модели - в момент завершения действия термической нагрузки в теле также циклически устанавливаются конечные или релаксированные напряжения (рис. 2, 3). Другое существенное отличие заключается в том, что в реальном материале после релаксации напряжений до нуля могут создаваться новые устойчивые атомные композиции вследствие того, что реальное тело не является сплошной изотропной средой, а имеет дискретную атомно-дислокационную структуру.
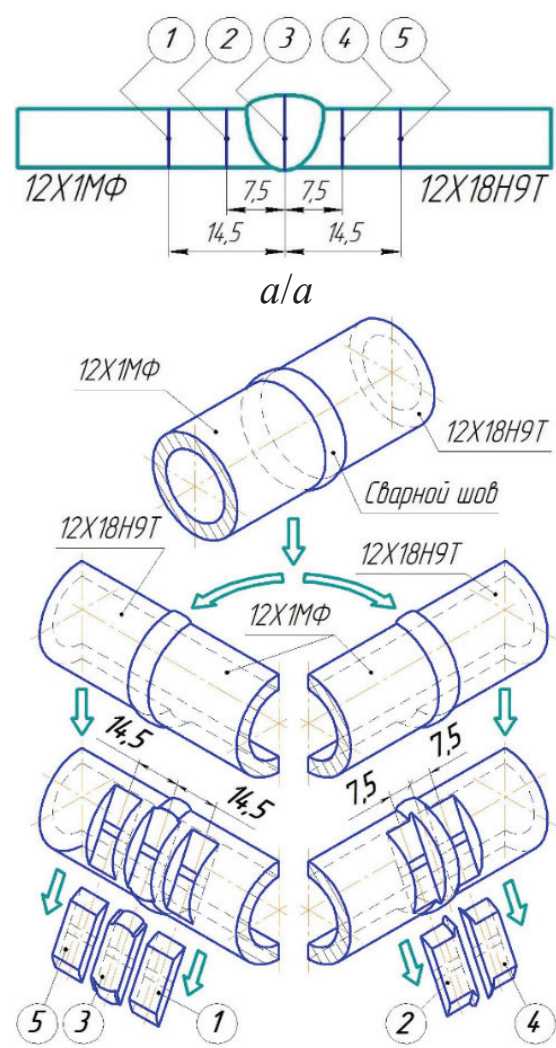

$\sigma / b$

Pис. 1. Сварной шов из разнородных сталей: а) схема шва; б) схема вырезки образцов: образцы № 1 и 2 (сталь $12 X 1 M Ф)$ вырезаны соответственно на расстоянии 14,5 и 7,5 мм от оси сварного шва; образец № 3 - из зоны сварного шва; образцы № 4 и 5 (сталь 12Х18H9T) вырезаны соответственно на расстоянии 7,5 и 14,5 мм от оси сварного шва

Fig. 1. Weld zone from dissimilar steels: a) weld design; b) scheme of specimen cutting: samples No. 1 and 2 (steel 12Cr1MoV) are cut at a distance of 14,5 and $7,5 \mathrm{~mm}$ from the weld axis, respectively; sample No. 3from the welding zone; Samples No. 4 and 5 (steel 12Cr18NigTi) are cut at a distance of 7,5 and $14,5 \mathrm{~mm}$ from the axis of the weld

Уменьшение напряжений (релаксация) обычно связывается с прочностью, означает разрыв межатомных связей и ослабление металла за счет образования трещин [25, 31]. За счет чисто пластических релаксаций на острие трещины, она может останавливаться в своем развитии или прорастать. Признаком прорастания микротрещины является глубокая (до нуля) релаксация напряжений [19, 20].

Основным микромеханизмом разрушения, таким образом, является разрыв межатомных связей, и, как следствие, релаксация внутренних напряжений по границам зерен или кристаллитов, накопление микротрещин в вакантных местах с образованием трещин критической длины. 


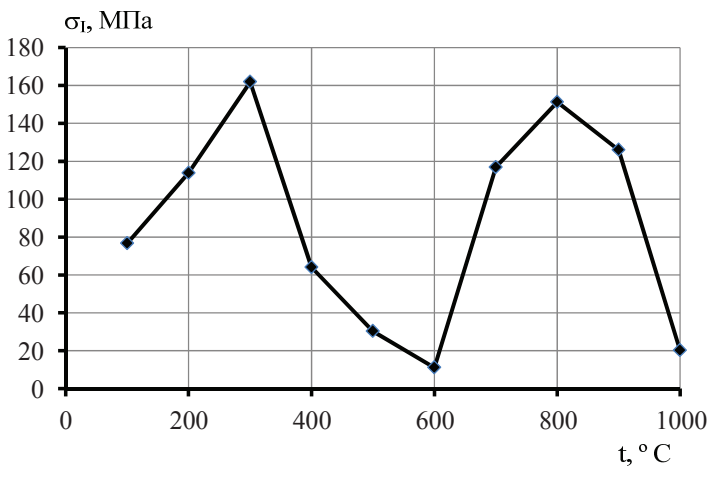

a/a

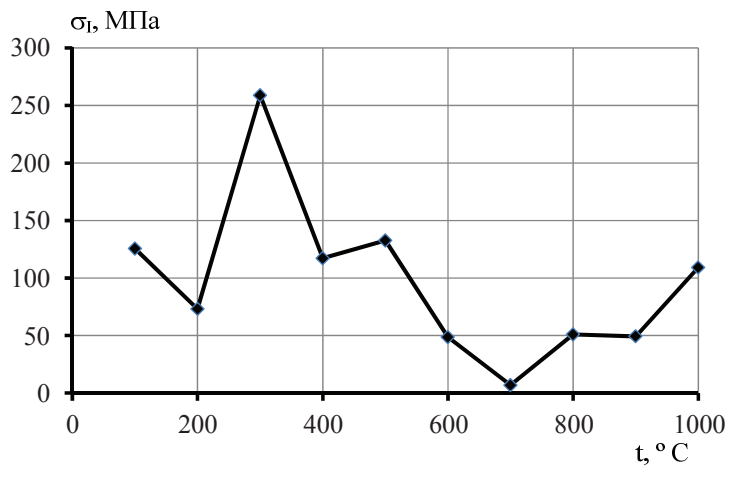

$\sigma / b$

Рис. 2. Распределение зональных напряжений в околошовной зоне при термоциклировании (сталь 12Х1МФ; образец № 2): а) наружная сторона; б) внутренняя сторона

Fig. 2. Distribution of zonal stresses in the weld-affected zone during heat cycling (steel 12Cr1MoV, sample No. 2): a) outside; b) inner side

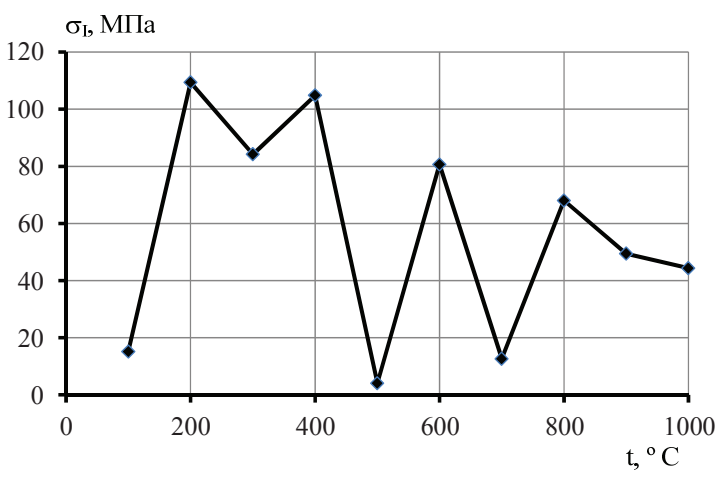

$a / a$

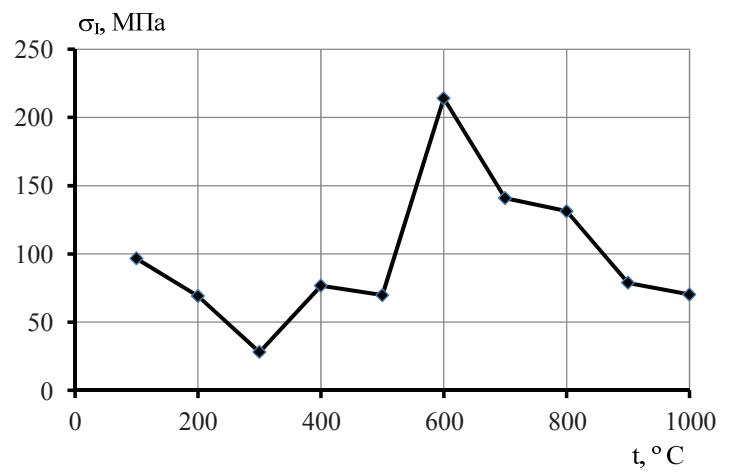

$\sigma / b$

Рис. 3. Распределение зональных напряжений в зоне термического влияния сварки при термоциклировании (сталь 12Х1МФ; образец № 1): а) наружная сторона; б) внутренняя сторона

Fig. 3. Zonal stresses distribution in the zone of thermal welding influence during heat cycling (steel 12Cr1MoV, sample No. 1): a) outside; b) inside

В образце № 2 просматриваются два момента глубокой (близкой к нулю) релаксации напряжений - 11 МПа на наружной поверхности при температуре $600{ }^{\circ} \mathrm{C}$ и $7 \mathrm{MПа} \mathrm{на} \mathrm{внутренней} \mathrm{поверхно-}$ сти при температуре порядка $650{ }^{\circ} \mathrm{C}$ (рис. 2).

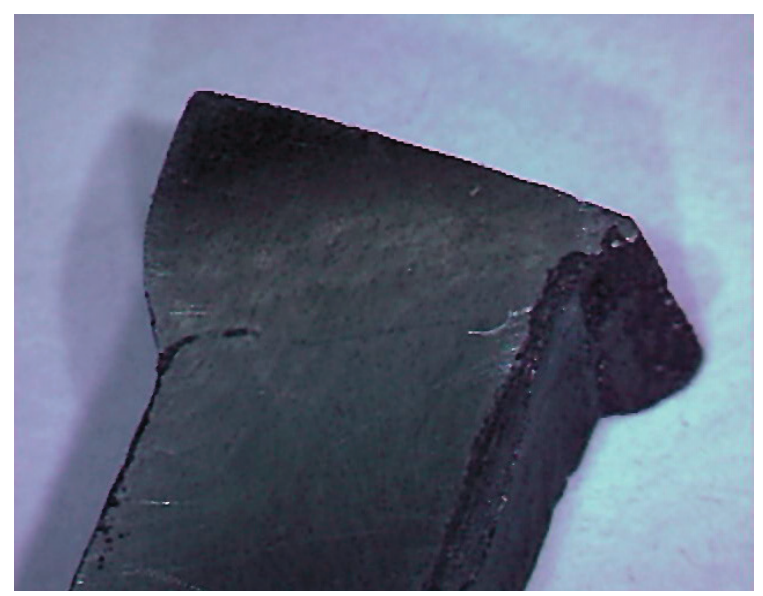

$a / a$
В образце № 1 признаки микротрещины сформировались на наружной стороне при температуре $500{ }^{\circ} \mathrm{C}\left(\sigma_{I}=4 \mathrm{M \Pi а}\right)$, рис. 3.

Накопление микротрещин спровоцировало наступление предельного состояния и разрушение.

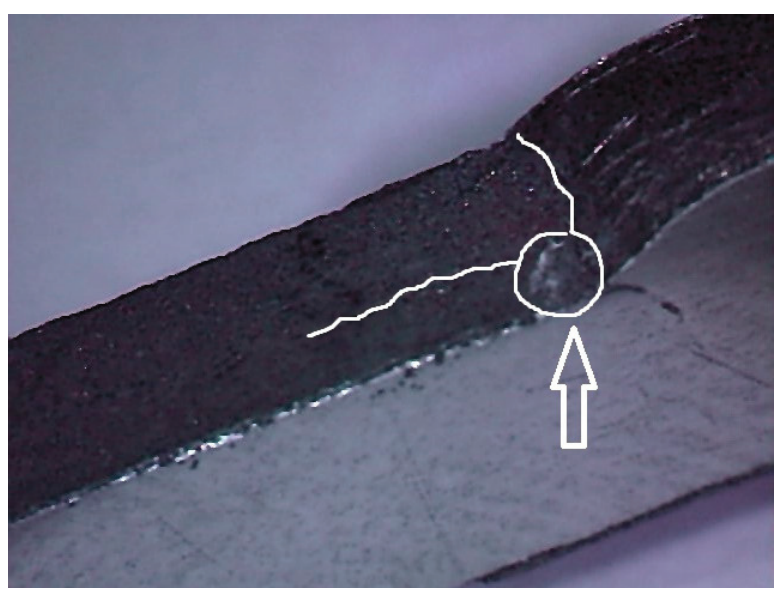

$\sigma / b$

Рис. 4. Трещина в околошовной зоне и зоне термического влияния сварки (сталь 12Х1МФ): а) вид сверху; б) вид сбоку

Fig. 4. Crack in the weld-affected zone and the welding heat-affected zone (steel 12(r1MoV): a) top view; b) side view 

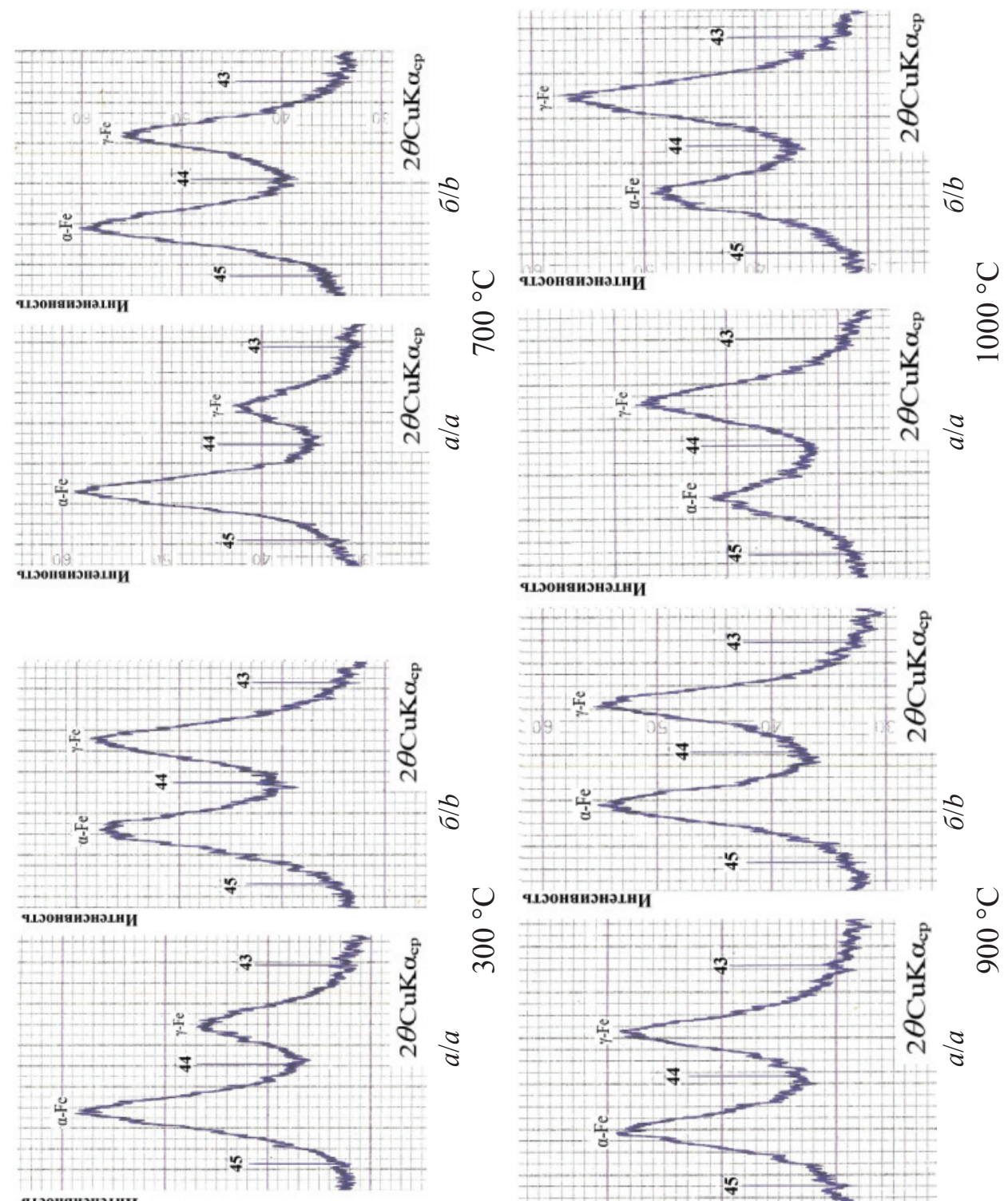

o
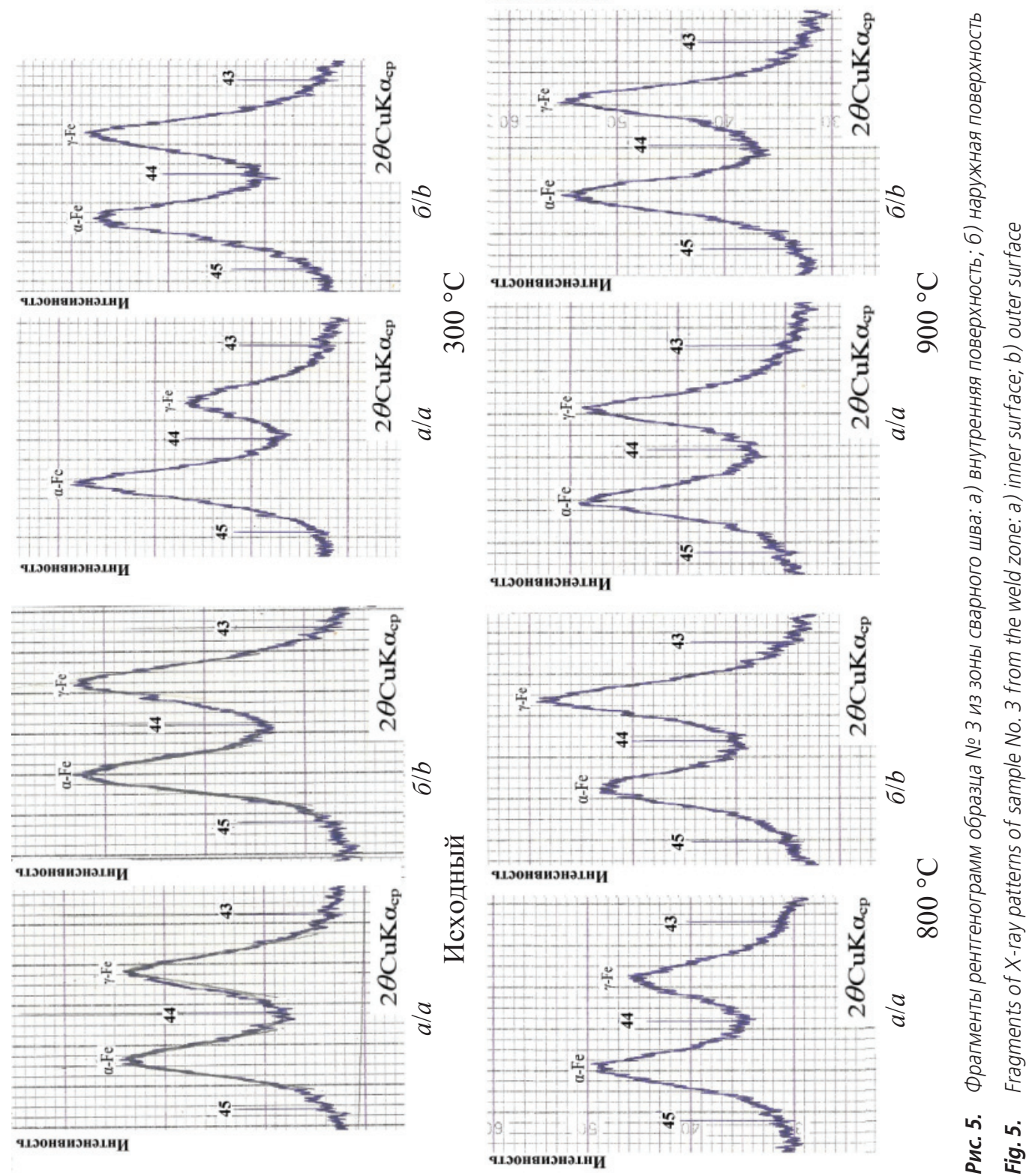
Моменты образования трещин определяются визуально и с применением соответствующих средств контроля (рис. 4).

\section{Экспериментальные результаты исследований распределения напряжений в зоне сварного шва. Образец № 3}

Образец № 3 из зоны сварного шва представляет собой двухфазную систему фаз в виде $\alpha$ - и $\gamma$-фаз железа. Концентрации фаз в процессе термоциклирования постоянно меняются. На рис. 5 представлены некоторые фрагменты этого процесса.

Концентрационные фазовые флуктуации проявляются в перераспределении зональных напряжений, что иллюстрируется на рис 6 .

Для обеих фаз внутренние напряжения в процессе термоциклирования изменяются от растягивающих $(+)$ до сжимающих через релаксацию (обнуление) напряжений.

На основании экспериментальных данных (рис. 6) можно установить систему структурных признаков предразрушения, которая однозначно совпадает с наступлением предельного состояния за счет разрушения:

- напряжения обеих фаз в структуре двухфазного сварного шва релаксируют одновременно. Одновременная релаксация для наружной поверхности наблюдается в диапазоне температур $400-500{ }^{\circ} \mathrm{C}$ (рис. 6). Релаксация рассматривается как создание микротрещины;

- в диапазоне температур 500-600 ${ }^{\circ} \mathrm{C}$ примерно в окрестности $550{ }^{\circ} \mathrm{C}$ наблюдается одновременное обнуление напряжений для обеих фаз;

- следующий цикл повышения температуры $\left(600{ }^{\circ} \mathrm{C}\right)$ сопровождается одновременным переходом зональных напряжений для $\alpha$ - и $\gamma$-фаз железа в зону растяжения. При этом трещины, образовавшиеся в процессе релаксации, теряют устойчивость и раскрываются за счет растягивающих напряжений.

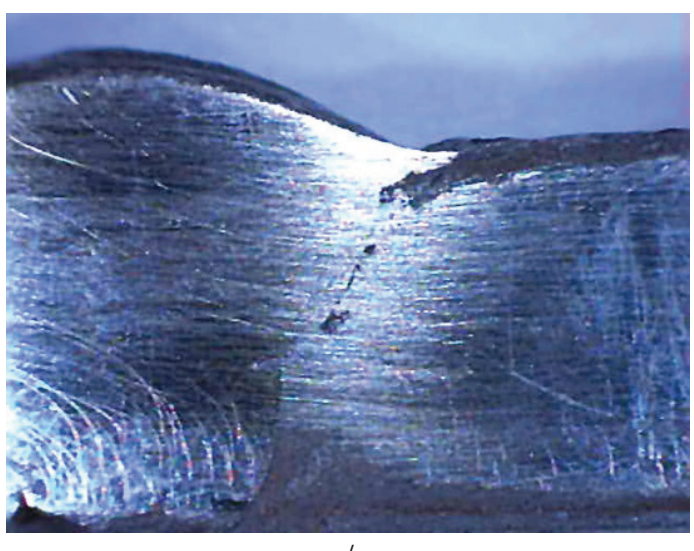

$a / a$ б, МПа

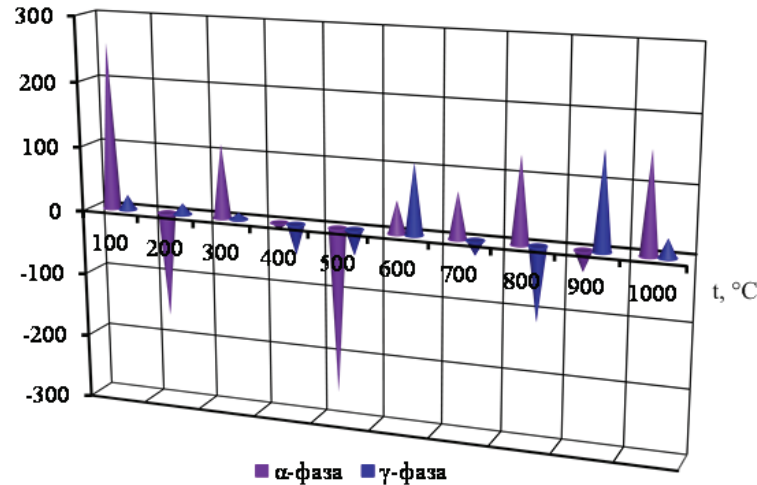

Рис. 6. Распределение зональных напряжений на наружной поверхности образца № 3 в зависимости от температуры термоциклирования

Fig. 6. Distribution of zonal stresses on the outer surface of sample No. 3 as a function of the heat cycling temperature

Разрушение, вероятнее всего, возникнет в межзеренных границах $\alpha$-фазы, так как растягивающее напряжение для $\gamma$-фазы больше (110 МПа для $\gamma$-фазы и 50 МПа для $\alpha$-фазы).

На основании изложенного можно заключить, что наружная поверхность исследованного сварного шва будет устойчивой к разрушению до температур порядка 500-550 ${ }^{\circ} \mathrm{C}$ (рис. 6). Этот экспериментальный факт может быть положен в основу диагностики прочности сварного узла как способ установления оптимальной температуры эксплуатации.

Гипотеза о прогнозировании роста трещины по условиям релаксации внутренних напряжений подтверждается на основе визуализации процесса образования трещины, которая визуально проявилась при температуре порядка $500{ }^{\circ} \mathrm{C}$, что привело к раскрытию трещины и разрушению шва в диапазоне температуре $550-600{ }^{\circ} \mathrm{C}$ (рис. 7).

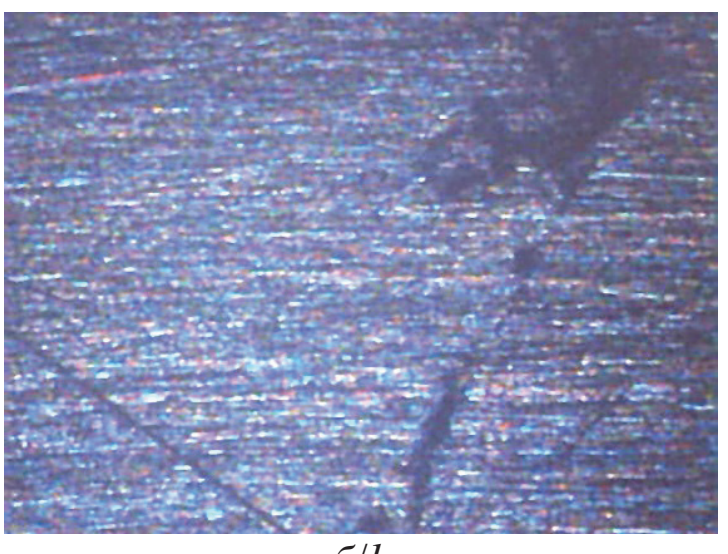

Рис. 7. Трещина в сварном узле разнородного сварного шва (12X1МФ+12Н18Н9T): а) общий вид; б) прорастание трещины в 30 ну сварного шва

Fig. 7. Crack in a weldment of a heterogeneous weld zone (12Cr1MoV+12H18H9T): a) general form; b) crack germination into the weld zone 
Разрушение, таким образом, можно рассматривать не как какое-то критическое событие, а как физический процесс зарождения, объединения и роста микротрещин. Этот процесс заканчивается потерей устойчивости одной из таких трещин. Таким образом, графики (рис. 6) являются контролирующими процесс образования микротрещин и разрушения, связанного с релаксацией внутренних остаточных напряжений, и могут определять область напряженных состояний, связанных с безопасной температурой эксплуатации.

Экспериментальные результаты исследований распределения напряжений в ОШЗ и ЗТВ в образцах из стали 12Х18Н9Т. Образцы № 4, 5

На рис. 8, 9 представлено распределение напряжений в образцах № 4,5 из околошовной зоны и зоны термического влияния сварки.

б, МПа

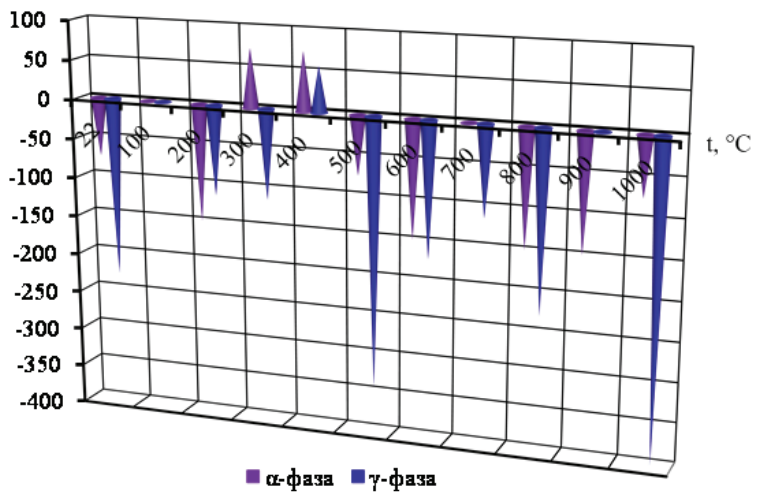

Рис. 8. Распределение зональных напряжений на наружной поверхности образца № 4 (ОШЗ)

Fig. 8. Zonal stresses distribution on the outer surface of sample No. 4 (WAZ)

б, МПа

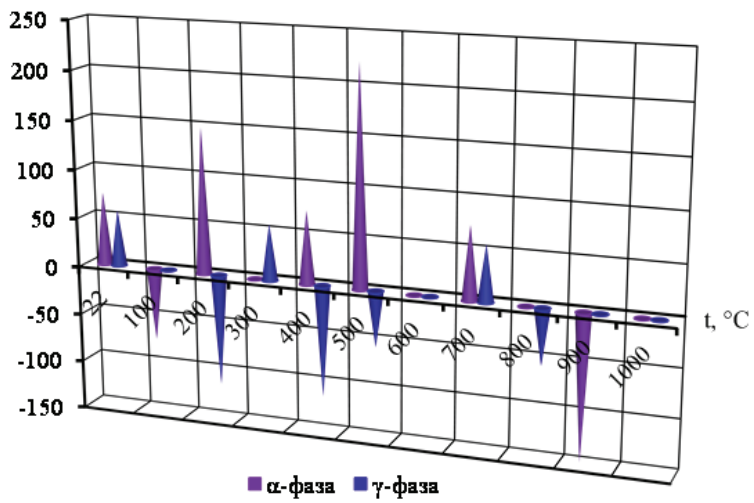

Рис. 9. Распределение зональных напряжений на наружной поверхности образца № 5 (ЗТВ)

Fig. 9. Zonal stresses distribution on the outer surface of sample No. 5 (WHAZ)

Анализ распределения напряжений в образце № 4 (ОШЗ) показывает, что условие одновременной релаксации с последующим одновременным переходом в зону растяжения не выполняется во всем пространстве напряжений. В частности, при температуре $500{ }^{\circ} \mathrm{C}$ наблюдается переход напряжений в сжимающую область, и далее напряжения сжатия сохраняются в диапазоне температур от 500 до $1000{ }^{\circ} \mathrm{C}$ (рис. 8). Область растягивающих напряжений отсутствует. В чем же роль межатомных связей при всестороннем равном сжатии? Дело в том, что из рис. 8 видно, что сжимающие напряжения нестабильны и изменяются по величине в процессе термоциклирования. Это говорит о том, что не бывает всесторонне равного сжатия, всегда будет существовать градиент напряжений. Это значит, что роль межатомных связей в процессах разрушения и в этом случае является ведущей и проявится с течением времени из-за градиента напряжений.

Как отмечалось, для разрушения необходимо выполнение условия одновременности процесса релаксации внутренних напряжений для обеих $\alpha$ и $\gamma$-фаз и одновременного перехода из области сжимающих напряжений в область растягивающих напряжений, способствующих раскрытию и росту микротрещин. Видно (рис. 9), что в зоне термического влияния сварки условие синхронной осцилляции напряжений не реализуется. Это объясняет отсутствие микротрещин в зоне термического влияния на данном этапе.

Известно, что в некоторых исследованиях в качестве критерия длительной прочности используют величину максимального нормального напряжения $\sigma_{1}$ или интенсивность касательных напряжений $\sigma_{i}$ [32]. Указанные варианты являются двумя возможными предельными случаями хрупкого и вязкого разрушения.

В действительности встречаются промежуточные состояния - разрушения смешанного характеpa, поэтому ни $\sigma_{1}$, ни $\sigma_{i}$ не могут быть критерием длительной прочности. Не может быть критерием и величина $1 / 2\left(\sigma_{1}+\sigma_{i}\right)$, так как он предполагает одинаковую и неизменную долю величин $\sigma_{1}$ и $\sigma_{i}$.

Внутренние напряжения отражают индивидуальные особенности материала, поэтому изложенный подход допускает возможность оценки момента разрыва для любого материала, с которым приходится иметь дело на практике - хрупкого или вязкого.

\section{Экспериментальные результаты исследований распределения напряжений в зонах сварного шва с начальной (сварочной) трещиной}

Повреждение сварного узла (рис. 10) не связано с условиями эксплуатации, оно обусловлено наличием в изделии сварочных напряжений в области стыка в результате технологического процесса, вызвавшего образование начальной, стабильно растущей трещины.

На рис. 11 представлена схема зон сварного узла для исследования химического состава. Результаты исследования помещены в таблице. 


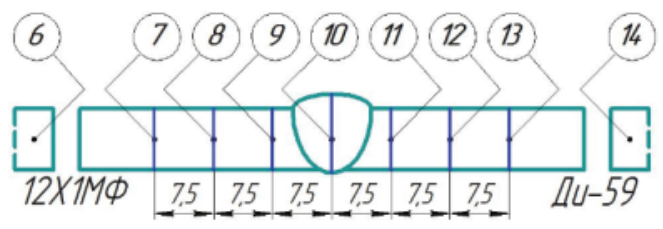

Рис. 10. Схема вырезки образцов из критических зон сварного узла: 6, 14 - эталонные образцы из сталей 12Х1МФ и Ди-59 соответственно; 9, 11 - образцы, вырезанные из околошовных зон на расстоянии 7,5 мм от оси сварного шва (ОШЗ); 10 - образец из зоны сварного шва; 8, 12 - образцы, вырезанные из зон термического влияния сварки на расстоянии 15 мм от оси сварного шва (3Тв); 7, 13 - образцы, вырезанные из зон на расстоянии 22,5 мм от оси сварного шва

Fig. 10. Scheme for cutting samples from the weldment critical zones: 6,14 are the reference specimens from $12 \mathrm{Cr} 1 \mathrm{MoV}$ and 10Cr13Mn12Si2Ni2Cu2Nb steels, respectively; 9, 11 are the specimens cut from weld-affected zones at a distance of 7,5 $\mathrm{mm}$ from the weld axis (WAZ); 10 is the specimen from the weld zone; 8,12 are the specimens cut from the welding heat-affected zone at a distance of $15 \mathrm{~mm}$ from the weld axis (WHAZ); 7, 13 are the specimens cut from zones at a distance of $22,5 \mathrm{~mm}$ from the weld axis

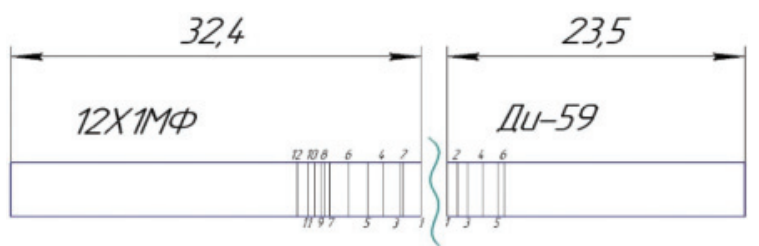

Рис. 11. Схема зон сварного шва для исследования химического состава

Fig. 11. Scheme of weld zone for chemical composition analysis

Наблюдается выраженная химическая неоднородность сварного шва и его критических зон (таблица).

На рис. 12 представлен фрагмент микроструктуры, включающий линию сплавления зон сварного шва. Рис. 12 иллюстрирует наличие развитой системы сформированных межкристаллитных трещин в околошовной зоне (образец № 9 по рис. 10).

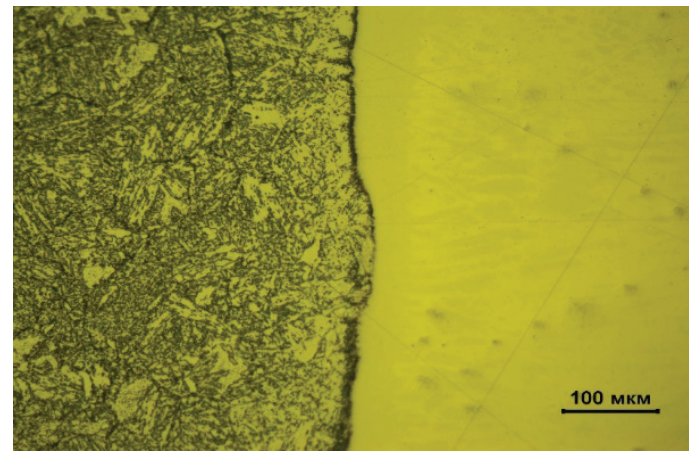

Рис. 12. Линия сплавления. Образец № 9 из околошовной зоны (слева сталь 12Х1МФ, справа Ди-59); ×200

Fig. 12. Fusion line. Sample No. 9 from the weld-affected zone (steel 12Cr1MoV is on the left, 10Cr13Mn12Si2Ni2Cu2Nb is on the right); $\times 200$

На рис. 13 представлен вид сварочной макротрещины в зоне сварного узла со стороны стали $2 Х 1 \mathrm{M}$.

На рис. 14 иллюстрируется микроструктура зоны термического влияния сварки, образец № 8 (по рис. 10).

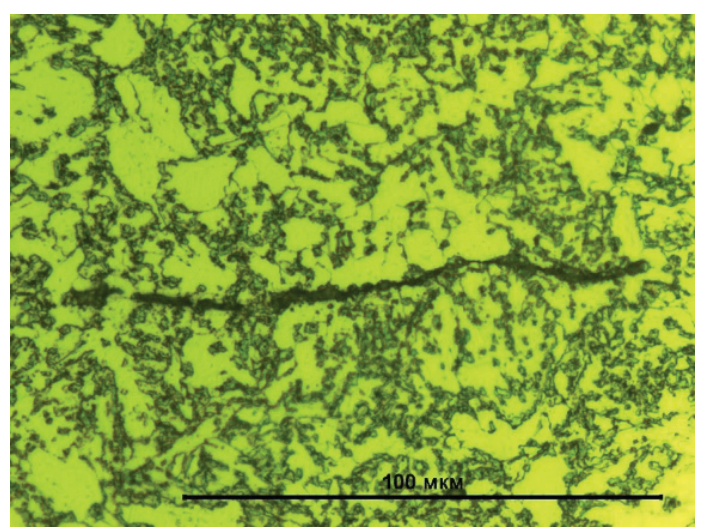

Рис. 14. Трещина в зоне термического влияния длиной до 122 мкм; ×1000 (сталь 12Х1МФ, образец № 8 по рис. 10)

Fig. 14. Crack in the welding heat-affected zone, which length is up to 122 microns; $\times 1000$ (steel 112 Cr1MoV, specimen No. 8 in Fig. 10)

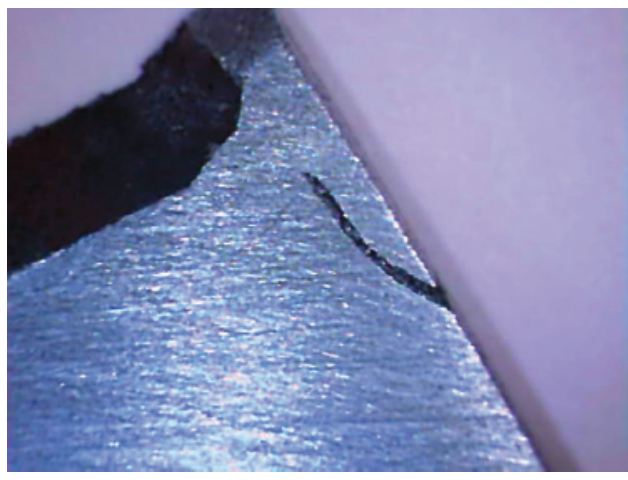

$a / a$

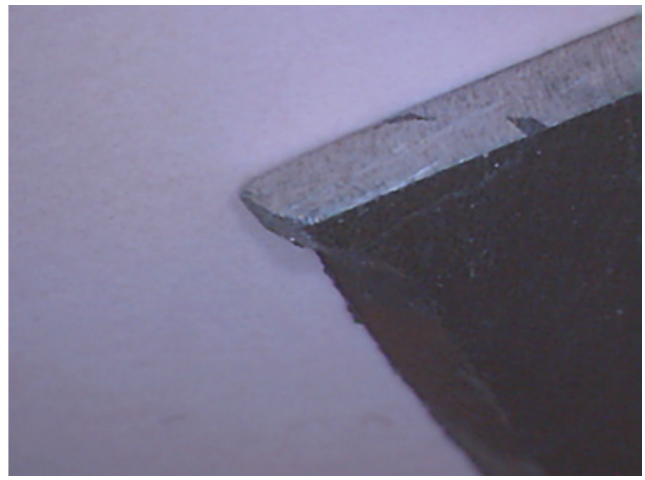

$\sigma / b$

Рис. 13. Видимая трещина в зоне сварного узла со стороны стали 12Х1МФ (образец № 9); ×100: а) вид наружной поверхности; б) распространение трещины по толщине стенки к зоне сварного шва

Fig. 13. Visible crack in the weldment zone on the steel 12Cr1MoV side (specimen No. 9); ×100: a) external surface type; b) crack germination along the wall thickness to the weld zone 
Таблица. Химический состав исследуемых зон сварного шва (по рис. 11)

Table. $\quad$ Chemical composition of the weld investigated zones (according to Figure 11)

\begin{tabular}{|c|c|c|c|c|c|c|c|c|c|c|c|c|c|c|c|c|}
\hline $\begin{array}{l}\text { Зоны } \\
\text { Zones }\end{array}$ & Mo & V & $\mathrm{Nb}$ & Ti & $\mathrm{Ni}$ & $\mathrm{Cu}$ & Si & $\mathrm{Mn}$ & $\mathrm{Cr}$ & $P$ & S & $C$ & Al & W & Co & As \\
\hline 1 & 0149 & 0,0221 & 0,0414 & 0 & 17,039 & 0,6091 & 0,0735 & 2,7132 & 22,2633 & 0 & 0 & 0,0015 & 0,0052 & 0,3272 & 0 & 0 \\
\hline 2 & 0,0304 & 0,0362 & 0,0629 & 0 & 16,3098 & 0,4908 & 0,2756 & 2,6928 & 20,9265 & 0,067 & 0,0444 & 0,0584 & 0,0084 & 0,3414 & 0 & 0 \\
\hline 3 & 0,0163 & 0,0262 & 0,0423 & 0 & 17,0082 & 0,5119 & 0,1068 & 2,6611 & 22,3409 & 0 & 0 & 0,0022 & 0,002 & 0,2904 & 0 & 0 \\
\hline 4 & 0,0151 & 0,0194 & 0,0377 & 0 & 18,5727 & 0,5841 & 0,0139 & 2,3075 & 22,4337 & 0,1177 & 0,0539 & 0,0014 & 0,0031 & 0,4432 & 0 & 0 \\
\hline 5 & 0,0255 & 0,0211 & 0,062 & 0 & 14,7496 & 0,857 & 0,1045 & 3,1691 & 18,9665 & 0 & 0 & 0,0005 & 0,0024 & 0,3843 & 0 & 0 \\
\hline 6 & 0,1236 & 0,0651 & 0 & 0,0032 & 0,1228 & 0,1312 & 0,833 & 0,3318 & 0,8293 & 0 & 0,017 & 0 & 0,0291 & 0 & 0,0076 & 0 \\
\hline 7 & 0,0231 & 0,107 & 0 & 0,0027 & 0,1362 & 0,1367 & 0,1332 & 0,4596 & 1,0417 & 0,0204 & 0,0185 & 0 & 0,0105 & 0 & 0,0111 & 0,8286 \\
\hline 8 & 0,011 & 0,0825 & 0 & 0,0029 & 0,1352 & 0,1393 & 0,0991 & 0,4009 & 0,9748 & 0 & 0,0034 & 0 & 0,0105 & 0 & 0,0096 & 1,6096 \\
\hline 9 & 0,1504 & 0,0827 & 0 & 0,0028 & 0,1289 & 0,1405 & 0,1049 & 0,3884 & 0,9656 & 0 & 0 & 0,0172 & 0,0149 & 0 & 0,0087 & 2,8856 \\
\hline 10 & 0,0428 & 0,1021 & 0 & 0,0024 & 0,1382 & 0,2661 & 0,13 & 0,4556 & 1,0376 & 0,2161 & 0,5858 & 0 & 0,0106 & 0 & 0,0112 & 1,42 \\
\hline 11 & 0,1841 & 0,1139 & 0 & 0,0024 & 0,1404 & 0,2578 & 0,1524 & 0,4808 & 1,0214 & 0,0652 & 0,0065 & 0 & 0,0111 & 0 & 0,012 & 0,7528 \\
\hline 12 & 0,2399 & 0,1499 & 0 & 0,0026 & 0,141 & 0,1601 & 0,2041 & 0,5286 & 1,055 & 0,0041 & 0,0044 & 0,0735 & 0,0113 & 0 & 0,0142 & 0,0614 \\
\hline 1 & 0 & 0,0071 & 0,3785 & 0,0023 & 2,7441 & 2,5695 & 0,6323 & 13,7428 & 14,0017 & 0,095 & 0,0474 & 0,0004 & 0,0227 & 0 & 0 & 0 \\
\hline 2 & 0 & 0,0057 & 0,3101 & 0 & 2,8574 & 2,6664 & 0,5591 & 13,9486 & 13,8001 & 0,0673 & 0,0388 & 0 & 0,0265 & 0,0001 & 0 & 0 \\
\hline 3 & 0 & 0,0059 & 0,3273 & 0 & 2,6835 & 2,5213 & 0,6421 & 14,3531 & 13,7078 & 0,1281 & 0,058 & 0 & 0,0204 & 0 & 0 & 0 \\
\hline 4 & 0 & 0,0067 & 0,3445 & 0 & 2,7725 & 2,5801 & 0,6243 & 13,5075 & 13,8936 & 0,1484 & 0,0617 & 0 & 0,0227 & 0 & 0 & 0 \\
\hline 5 & 0 & 0,0065 & 0,3511 & 0 & 2,7475 & 2,669 & 0,6194 & 14,0355 & 13,8956 & 0,2286 & 0,0881 & 0 & 0,0281 & 0 & 0 & 0 \\
\hline 6 & 0 & 0,0038 & 0,2145 & 0,01 & 3,3507 & 3,0683 & 0,3288 & 12,1932 & 13,3573 & 0,0336 & 0,0221 & 0 & 0,0203 & 0 & 0 & 0 \\
\hline
\end{tabular}

На рис. 15 представлены фрагменты рентгенограмм из зоны сварного шва (образец № 10 по рис. 10). Обе поверхности зоны шва имеют смешанную фазовую структуру с разными концентрациями $\alpha$ и $\gamma$-фаз железа. Концентрации фаз отличаются также для наружной и внутренней поверхностей. Слева (сталь 12Х1МФ) и справа от зоны сплавления (сталь Ди-59) исходные структуры (непосредственно после сварки) однофазные.

Со стороны стали Ди-59 в образцах № 6, 7 и 8 также наблюдаются готовые трещины, некоторые фрагменты которых иллюстрируются на рис. 16.

Результаты выполненных оценок напряженного состояния зон сварного узла с начальной трещиной приведены на рис. 17.

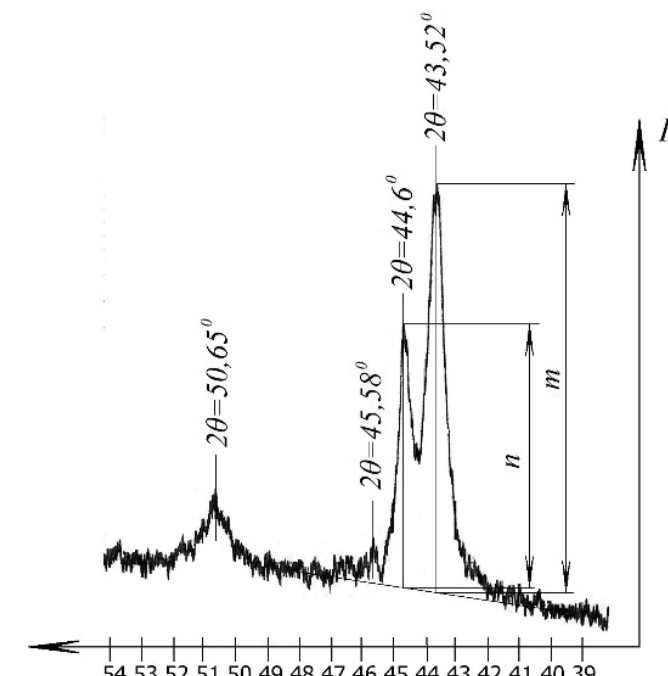
20, град

54535251504948474645444342414039

$a / a$
На основании сформулированного условия трещинообразования (рис. $2,3,6,8,9$ ) и полученных данных визуализации структурных трещин (рис. $12,13,14,16)$ признаком наличия технологической трещины, появившейся в результате сварочного процесса, могут быть релаксированные напряжения. Это условие справедливо для образцов № $7,8,9,11,12,13$. Непосредственно для двухфазной зоны сварного шва (образец № 10, рис. 17) условие синхронной релаксации внутренних напряжений не соблюдается, в этой зоне наличие трещин также не установлено.

Целостность зоны сварного шва подтверждается измерениями микротвердости (рис. 18). Микротвердость определялась по всей длине продольного

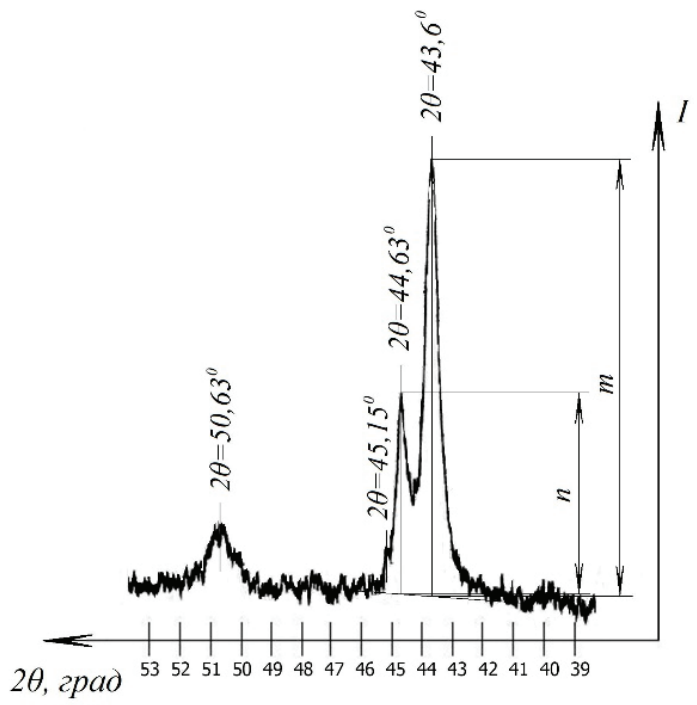

$\sigma / b$

Рис. 15. Фрагмент рентгенограммы зоны шва (образец № 10): а) наружная поверхность; б) внутренняя поверхность

Fig. 15. Roentgenogram fragment of the weld zone (sample No. 10): a) outer surface; $b$ ) inner surface 


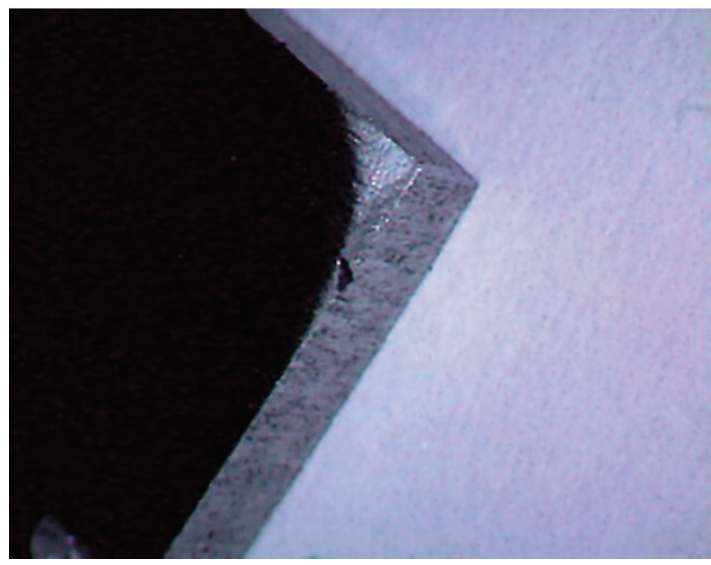

$a / a$

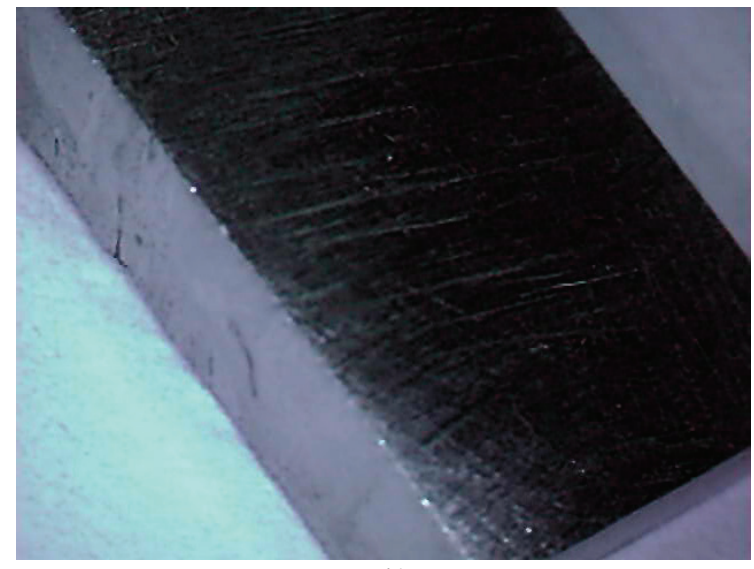

$\sigma / b$

Рис. 16. Видимые разрушения в образцах № 11 и 12 стали Ди-59: а) трещина в образце № 11, переходящая к зоне сплавления; б) хрупкая поперечная трещина в образце № 12

Fig. 16. Visible fractures in samples No. 11 and 12 of 10Cr13Mn12Si2Ni2Cu2Nb steel: a) crack in sample No. 11, passing to the fusion zone; b) brittle transverse crack in sample No. 12

$\sigma_{\mathrm{l}}, \mathrm{MПа}$

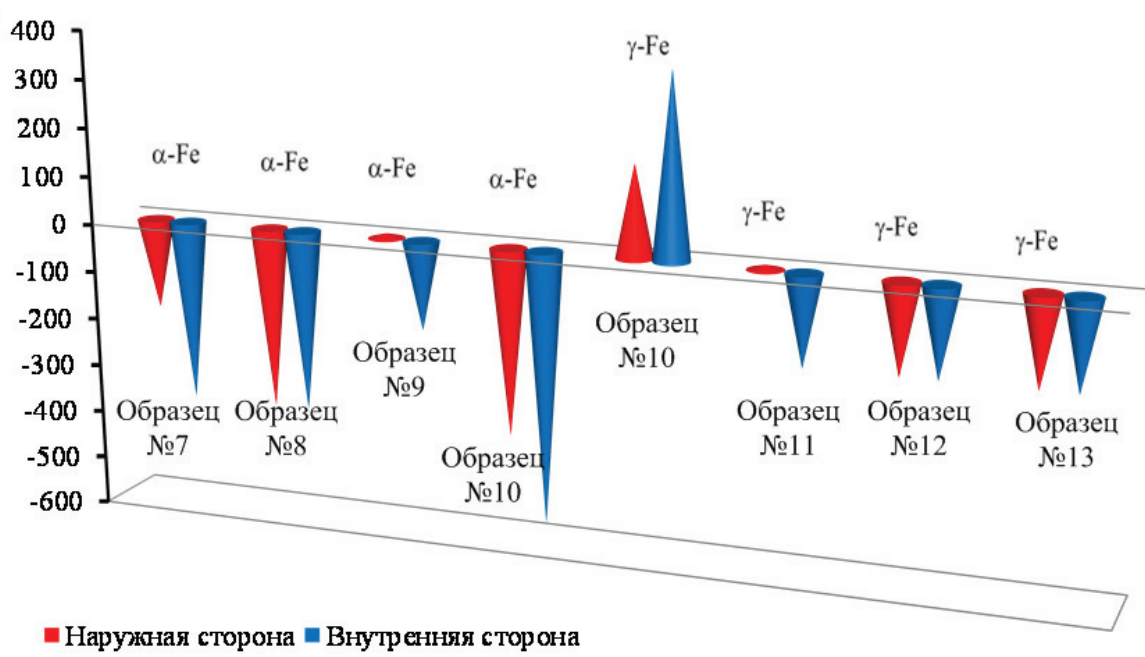

Рис. 17. Схема распределения внутренних напряжений в зонах сварного узла с начальной трещиной (исходное состояние)

Fig. 17. Distribution diagram of internal stresses in the weldment zones with an initial crack (initial state)

\section{Hv, МПа}

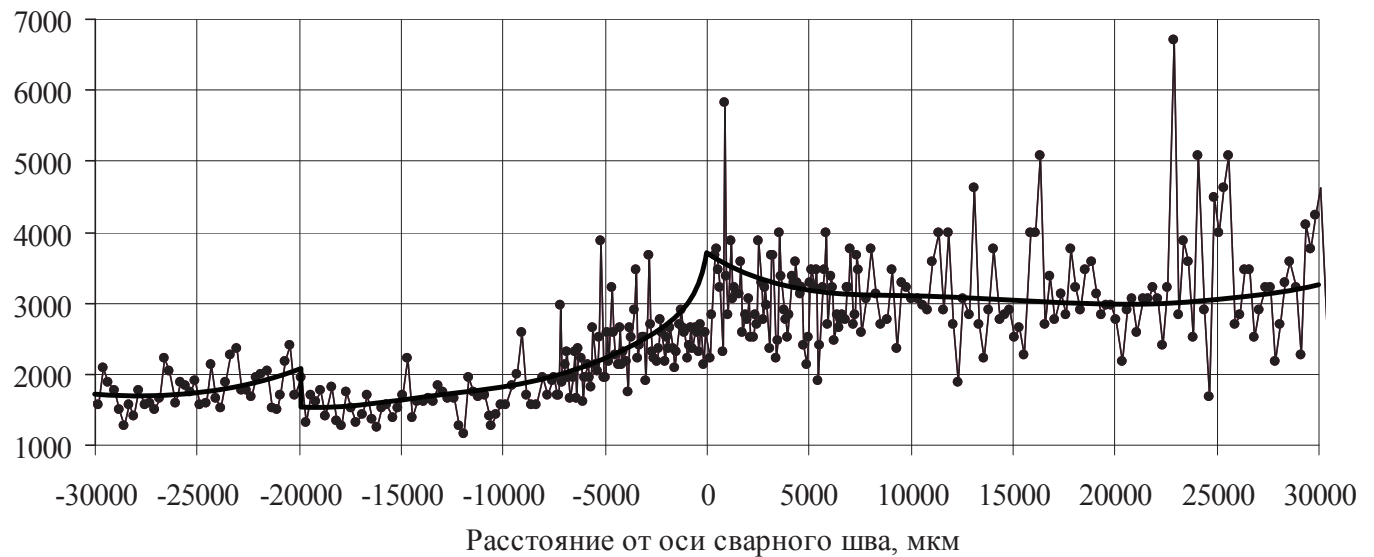

Рис. 18. Распределение микротвердости по длине продольного образца (зоны 7-13 по рис. 10)

Fig. 18. Microhardness distribution along the length of the longitudinal specimen (zones 7-13 in Fig. 10) 


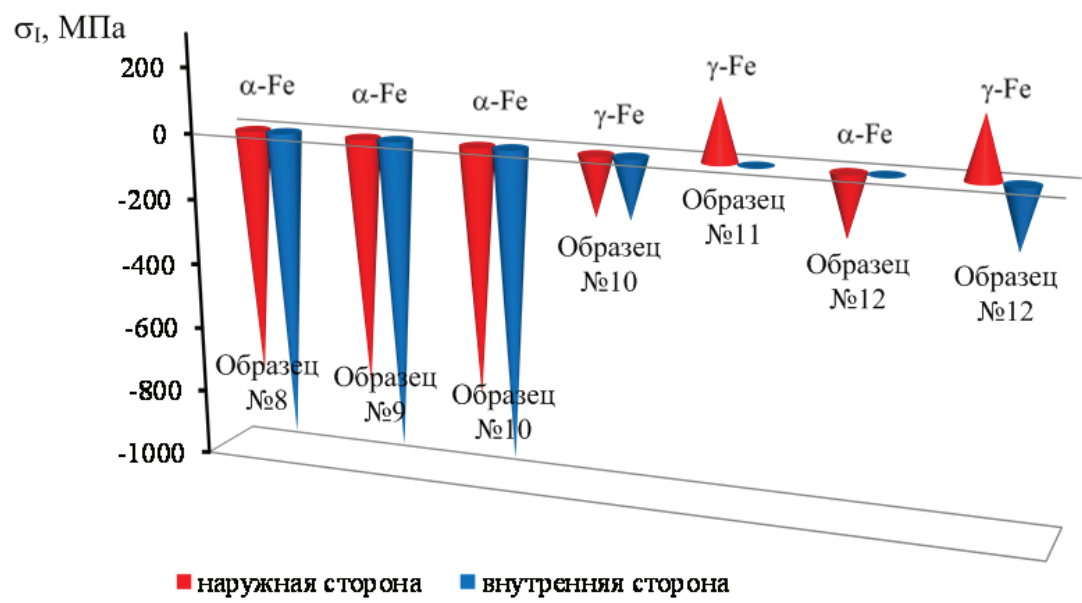

Рис. 19. Схема распределения напряжений первого рода (зональных) в зонах сварного узла с начальной трещиной после 9000 часов естественного старения в нормальных условиях

Fig. 19. Distribution diagram of the first kind stresses (zonal) in weldment zones with initial crack after 9000 hours of natural aging under normal conditions

образца с шагом 500 мкм. В зоне сварного шва шаг измерения составлял 100 мкм.

Анализ распределения микротвердости позволяет заключить, что тело шва является наиболее твердой и прочной зоной сварной конструкции.

На рис. 19 представлена схема распределения напряжений первого рода в зонах сварного узла с начальной трещиной после порядка 9000 часов естественного старения в нормальных условиях.

Процесс естественного старения привел к следующим существенным эффектам (рис. 19):

- в зоне шва (образец № 10) наблюдается одновременная релаксация $\alpha$ - и $\gamma$-фаз железа, что свидетельствует о наступлении состояния предразрушения в зоне сварного шва;

- существенно увеличился уровень сжимающих напряжений в зонах № 8 и 9 , а также в альфафазе образца № 10 (практически в два раза от $\sim 400$ до $\sim 800 \mathrm{MПа),} \mathrm{что} \mathrm{свидетельствует} \mathrm{о} \mathrm{рас-}$ ширении берегов всех существующих до этого момента трещин за счет сжатия фрагментов микроструктуры, которые в окружении свободных поверхностей стали вести себя как независимые объекты, не связанные атомными связями с другими фрагментами микроструктуры;

- образец № 11 остался однофазным, но напряжения из сжимающей области деформаций (рис. 17) перераспределились в растягивающую область (рис. 19), что, по признакам, соответствует раскрытию трещин в зоне № 11 ;

- образец № 12 претерпел фазовое превращение по типу $\gamma_{0} \rightarrow \gamma+\alpha$. Распад твердого раствора наблюдается как на наружной, так и на внутренней стороне и сопровождается сложным перераспределением полей внутренних напряжений.

Эти результаты свидетельствуют о непрерывности структурных превращений и связанных с этим процессов разрушения, которые протекают как бы самопроизвольно, без дополнительной внешней нагрузки, но под влиянием весьма сильного факто- ра, такого как неоднородные внутренние напряжения, зависящие от химической негомогенности (табл. 1), фазовой неоднородности (рис. 5, 15) и неоднородных распределений микротвердости (рис. 18).

Влияние неоднородности напряженного состояния на прочность трудно оценить теоретически, так как коэффициент неоднородности определяют из сравнения расчетных пределов прочности с соответствующей прочностью образцов [22], которая, не являясь величиной постоянной, осциллирует в диапазоне значений, отражающих индивидуальные структурные и ресурсные особенности материала, которые могут как снижать, так и увеличивать чувствительность стали к виду напряженного состояния.

Таким образом, экспериментальное определение условий релаксации внутренних напряжений (рис. $2,3,6,8,9)$, при которых создаются «благоприятные» условия для возникновения и роста трещин, гарантирует достоверность оценок корреляции вида напряженного состояния с трещинообразованием во всем пространстве критических зон сварного узла.

\section{Выводы}

1. Исследована гипотеза о корреляции механизма разрушения с процессами релаксации внутренних напряжений. Показано, что появление и рост трещины и релаксация напряжений являются взаимосвязанными процессами.

2. При термоциклических испытаниях в результате термофлуктуационных релаксаций обнаружены одни и те же качественные закономерности для однофазной и двухфазной системы фаз, приводящие к разрушению:

- рост трещины в однофазной системе совпадает по времени с процессом, происходящим в момент глубокой релаксации внутренних зональных напряжений; 
- рост трещины в двухфазной $(\alpha+\gamma)$ системе рассматривается как два взаимосвязанных между собой процесса, происходящих при условии одновременной для обеих фаз релаксации с одновременным переходом действующих напряжений в растягивающую область в очередном цикле нагружения.

3. Для образца с начальной трещиной в условиях отсутствия внешних нагрузок и деформаций протекающие в образце процессы естественного старения контролируются только внутренними

\section{СПИСОК ЛИТЕРАТУРЫ}

1. Reasons for and nature of weld joints failure in hot reheat steam lines of 800-MW power units / A.E. Anokhov, E.A. Grin, T.V. Perevezentseva, I.V. Fedina // Thermal Engineering. - 2009. V. 56. - № 2. - P. 113-119.

2. Grin E.A., Zelenskii A.V. Studying the stressed state and operating characteristics of high-pressure deaerators' metal and assessment of their longevity // Thermal Engineering. - 2009. V. 56. - № 2. - P. 103-112.

3. Pan Jian-hua, Fan Zhi-cao, Zong Ning-sheng. Research on weld cracking of TP321H stainless steel pipeline under elevated temperature // International Journal of Pressure Vessels and Piping. 2016. - V. 148. - P. 1-8.

4. Minin S.I., Trofimov A.I., Trofimov M.A. The technology of thermal welding of the circulation piping of NPPS containing the influence of ultrasound // Nuclear Energy and Technology. 2017. - V. 3. - № 1. - P. 6-9.

5. Huang Tengfei, Zhang Guihe, Liu Feihua. Design, manufacturing and repair of tube-to-tube sheet welds of steam generators of CPR1000 units // Nuclear Engineering and Design. - 2018. V. $333 .-$ P. $55-62$.

6. Sorrentino $\mathrm{S}$. Welding technologies for ultra-supercritical power plant materials // Materials for Ultra-Supercritical and Advanced Ultra-Supercritical Power Plants. - 2017. - P. 247-319.

7. Исследование сенсибилизации околошовной зоны сварных соединений для подтверждения эффективности высокотемпературной термообработки аустенитных трубопроводов ДУ300 АЭС с реакторами РБМК-1000 / Н.В. Васильев, Г.П. Карзов, А.А. Блюмин, П.И. Боркин // Вопросы материаловедения. -2016 . - № 1 (85). - С. 99-107.

8. Богачев В.А., Таран 0.Е. Влияние тепловой неравномерности на температуру и надежность металла конвективных пароперегревателей // Электрические станции. - 2002. - № 2. C. 21-24.

9. Сорокин Л.С. Исследование остаточных напряжений в сварных соединениях труб из стали 12Х1МФ // Электрические станции. - 1994. - № 8. - С. 14-15.

10. Влияние послесварочной обработки на структурные особенности сварных соединений сталей 20 и 30ХГСА / С.В. Горбачев, А.П. Фот, А.М. Щипачев, Р.Я. Лутфуллин // Вестник Оренбургского государственного университета. - 2015. № 4 (179). - C. $159-164$.

11. Popov A.B. Main factors causing damage to the high-temperature heating surfaces used in power-generating boilers // Thermal Engineering. - 2011. - V. 58. - № 2. - P. 101-108.

12. Residual stress distributions in arc, laser and electron-beam welds in $30 \mathrm{~mm}$ thick SA508 steel: a cross-process comparison / J. Balakrishnan, A.N. Vasileiou, J.A. Francis, M.C. Smith, M.J. Roy, M.D. Callaghan, N.M. Irvine // International Journal of Pressure Vessels and Piping. - 2018. - V. 162. - P. 59-70.

13. Residual stress measurement round robin on an electron beam welded joint between austenitic stainless steel $316 \mathrm{~L}(\mathrm{~N})$ and ferritic steel P91 / Y. Javadi, M.C. Smith, K.Abburi Venkata, N. Na- напряжениями, которые приводят в действие все механизмы разрушения, в том числе и фазовый распад.

4. По условиям термофлуктуационной релаксации внутренних напряжений устанавливается температурная граница области напряженных состояний, определяющая надежную эксплуатационную температуру.

Работа выполнена при поддержке РФФИ «Фундаментальные основы инженерных наук» (проекты № 15-08-99544a в 2014 2., № 18-08-01265 в 2018 г.).

veed, A.N. Forsey, J.A. Francis, R.A. Ainsworth, C.E. Truman, D.J. Smith, F. Hosseinzadeh, S. Gungor, P.J. Bouchard, H.C. Dey, A.K. Bhaduri, S. Mahadevan // International Journal of Pressure Vessels and Piping. - 2017. - V. 154. - P. 41-57.

14. РД 153-34.1-003-01. Сварка, термообработка и контроль трубных систем котлов и трубопроводов при монтаже и ремонте энергетического оборудования (РТМ-1c). - М.: ПИО ОБТ, 2002. -190 c.

15. С0 153-34.17.464-2003. Инструкция по продлению срока службы трубопроводов II, III и IV категорий. - М.: ЦПТИ ОРГРЭС, 2004. - $146 \mathrm{c.}$

16. Когаев В.П. Расчеты на прочность при напряжениях, переменных во времени / под ред. А.П. Гусенкова. - М.: Машиностроение, 1993. - $364 \mathrm{c}$.

17. Measures for Ensuring Reliable Operation of the Welded Joint Connecting the Reactor Coolant Circuit's Header to the Shell of a Steam Generator Used at a VVER-1000 Reactor-Based Nuclear Power Station / S.A. Kharchenko, N.B. Trunov, N.F. Korotaev, S.L. Lyakishev // Thermal Engineering. - 2011. - V. 58. № 3. - P. 208-214.

18. Dubov A.A. Problems in estimating the remaining life of aging equipment // Thermal Engineering. - 2003. - V. 50. - № 11. P. $935-938$

19. The effect of thermo-mechanical loading on fracture-related parameters of austenitic steel / L.L. Lyubimova, A.A. Tashlykov, R.B. Tabakaev, A.A. Levin, A.Y. Popov // Engineering Failure Analysis. - 2017. - V. 81. - P. 45-56.

20. Changes in the State of Heat-Resistant Steel Induced by Repeated Hot Deformation / L.L. Lyubimova, R.N. Fisenko, A.A. Tashlykov, R.B. Tabakaev // Metals and Materials International. 2018. - V. 24. - № 1. - P. 121-129.

21. Hsin Jen Hoh, John Hock Lye Pang, Kin Shun Tsang. Stress intensity factors for fatigue analysis of weld toe cracks in a girthwelded pipe // International Journal of Fatigue. - 2016. V. 87. - P. 279-287.

22. Кудрявцев И.В., Наумченков Н.Е. Усталость сварных конструкций. - М.: Машиностроение, 1976. - 270 с.

23. Adiban S.V., Ramu M. Study on the effect of weld defects on fatigue life of structures // Materials Today. - 2018. - V. 5. - № 9. P. 1. - P. 17114-17124.

24. Present state of the problem of managing the service life of steam generators used at nuclear power stations equipped with VVER reactors / N.B. Trunov, S.E. Davidenko, V.S. Popadchuk, N.N. Davidenko, A.A. Berezanin, D.F. Gutsev, V.N. Lovchev, D.A. Usanov // Thermal Engineering. - 2011. - V. 58. - № 3. - P 184-189.

25. Welding residual stresses as needed for the prediction of fatigue crack propagation and fatigue strength / J. Hensel, T. NitschkePagel, D. Tchoffo Ngoula, H.-Th. Beier, D. Tchuindjang, U. Zerbst // Engineering Fracture Mechanics. - 2018. V. 198. - P. 123-141.

26. Способ установления состояния предразрушения конструкционного изделия: пат. Рос. Федерация № 2613486; заявл. 21.12.15; опубл. 16.03.17, Бюл. № 8. - 18 с. 
27. Екобори Т. Физика и механика разрушения и прочности твердых тел. - М.: Металлургия, 1971. - 264 с.

28. Партон В.З., Морозов Е.М. Механика упруго-пластического разрушения. - М.: Наука, 1974. -416 c.

29. Серенсен С.В. Сопротивление материалов усталостному и хрупкому разрушению. - М.: Атомиздат, 1975. - 192 с.

30. Мороз Л.С. Механика и физика деформаций и разрушения материалов. - Л.: Машиностроение, Ленингр. отделение, 1984. $224 \mathrm{c}$.
31. Friedel J., Gullity B.D., Crussard C. Study of the surface tension of a grain boundary in a metal as a function of the orientation of the two grains which the boundary separates // Acta Metallurgica. - 1953. - V. 1. - P. 79-92.

32. Бугай Н.В., Березина Т.Г., Трунин И.И. Работоспособность и долговечность металла энергетического оборудования. - М.: Энергоатомиздат, 1994. - 272 с.

Поступила 24.09.2018 г.

\section{Информация об авторах}

Заворин A.C., доктор технических наук, профессор научно-образовательного центра И.Н. Бутакова Национального исследовательского Томского политехнического университета.

Любимова Л.Л., кандидат технических наук, доцент научно-образовательного центра И.Н. Бутакова Национального исследовательского Томского политехнического университета.

Буваков К.B., кандидат технических наук, доцент научно-образовательного центра И.Н. Бутакова Национального исследовательского Томского политехнического университета.

Kyлеш A.C., аспирант научно-образовательного центра И.Н. Бутакова Национального исследовательского Томского политехнического университета.

Tашлыков A.A., кандидат технических наук, доцент научно-образовательного центра И.Н. Бутакова Национального исследовательского Томского политехнического университета.

$\boldsymbol{K} \boldsymbol{y}$ леш P.H., кандидат технических наук, доцент научно-образовательного центра И.Н. Бутакова Национального исследовательского Томского политехнического университета. 


\title{
INFLUENCE OF RESIDUAL STRESSES ON RESISTANCE TO BRITTLE FRACTURE IN WELDMENT ZONES
}

Alexander S. Zavorin', zavorin@tpu.ru

\author{
Lyudmila L. Lyubimova', \\ II@tpu.ru
}

\author{
Konstantin V. Buvakov', \\ buvakov@tpu.ru
}

\author{
Aygul S. Kulesh', \\ ronikul@tpu.ru
}

\author{
Alexander A. Tashlykov', \\ tashlykov@tpu.ru \\ Roman N. Kulesh', \\ ronikul@tpu.ru
1 National Research Tomsk Polytechnic University, 30, Lenin Avenue, Tomsk, 634050, Russia.

\begin{abstract}
The relevance of the research in the field of welded joints strength and failure is associated with the necessity of ensuring high operational reliability and safety running hazardous production facilities. Internal stresses and their relaxation as an independent cause of destruction are widely recognized nowadays. The final form of the maximum permissible state is cracks appearance, however the signs of the appeared maximum permissible state of the node or structure are not clearly defined.

The aim of the research is to establish the signs of weld zone pre-fracture and fracture under redistribution conditions of internal stresses during thermal relaxation.

The subject of the research is welded superheater units made of dissimilar steels.

Research methods: physical modeling of operating conditions by thermal cycling of samples in the MIMP-10UE electric furnace, $X$-ray dosimetry of the samples, internal structural stresses evaluation on DRON-type X-ray diffractometers, morphological analysis using the "Resource S7》 metallographic analyzer, including an inverted Olympus GF41 microscope with the SIAMS Photolab software, cracks morphology with a PEN SCKOPE microanalyzer, microhardness analysis using a PMT-3 microhardness tester.

Results. According to the hypothesis of crack formation correlation with internal stress relaxation, crack appearance and growth and stress relaxation are interrelated processes. As a result of thermal fluctuation relaxation, the same qualitative regularities (which lead to destruction) for a single-phase and two-phase system are found. Natural aging processes occurring in the sample with an initial crack in the absence of external loads and deformations are controlled only by internal stresses that activate all mechanisms of destruction, including phase decay. Under the conditions of internal stresses thermofluctuation relaxation, the temperature limit of the stress state region is set, which determines the reliable operating temperature.
\end{abstract}

\section{Key words:}

Weldment, weld-affected zone, welding heat-affected zone, internal stresses,

heat cycling, thermal relaxation, microhardness, crack formation.

The research was supported by the RFBR «Fundamental bases of engineering sciences» (projects no. 15-08-99544a, 2014, 18-08-01265, 2018).

\section{REFERENCES}

1. Anokhov A.E., Grin E.A., Perevezentseva T.V., Fedina I.V. Reasons for and nature of weld joints failure in hot reheat steam lines of 800-MW power units. Thermal Engineering, 2009, vol. 56, no. 2, pp. 113-119.

2. Grin E.A., Zelenskii A.V. Studying the stressed state and operating characteristics of high-pressure deaerators' metal and assessment of their longevity. Thermal Engineering, 2009, vol. 56, no. 2, pp. 103-112.

3. Pan Jian-hua, Fan Zhi-cao, Zong Ning-sheng. Research on weld cracking of TP321H stainless steel pipeline under elevated temperature. International Journal of Pressure Vessels and Piping, 2016, vol. 148, pp. 1-8.

4. Minin S.I., Trofimov A.I., Trofimov M.A. The technology of thermal welding of the circulation piping of NPPS containing the in- fluence of ultrasound. Nuclear Energy and Technology, 2017, vol. 3 , no. 1, pp. 6-9.

5. Huang T., Zhang G., Liu F. Design, manufacturing and repair of tube-to-tubesheet welds of steam generators of CPR1000 units. Nuclear Engineering and Design, 2018, vol. 333, pp. 55-62.

6. Sorrentino S. Welding technologies for ultra-supercritical power plant materials. Materials for Ultra-Supercritical and Advanced Ultra-Supercritical Power Plants, 2017, pp. 247-319.

7. Vasilyev N.V., Karzov G.P., Blyumin A.A., Borkin P.I. Issledovanie sensibilizatsii okoloshovnoy zony svarnykh soedineniy dlya podtverzhdeniya effektivnosti vysokotemperaturnoy termoobrabotki austenitnykh truboprovodov DU300 AES s reaktorami RBMK-1000 [The research of the sensitization of the welded joint zone to confirm the efficiency of high-temperature heat treatment of austenitic pipelines DU300 NPPs with RBMK- 
1000 reactors]. Voprosy materialovedeniya, 2016, no. 1 (85), pp. 99-107.

8. Bogachev V.A. Taran 0.E. Vliyanie teplovoy neravnomernosti na temperaturu i nadezhnost metalla konvektivnykh paroperegrevateley [Thermal unevenness influence on the quality and reliability of convective metal superheaters]. Elektricheskie stantsii, 2002, no. 2, pp. 21-24.

9. Sorokin L.S. Issledovanie ostatochnykh napryazheniy v svarnykh soedineniyakh trub iz stali 12H1MF [The research of residual stresses in welded joints of steel 12H1MF pipes]. Elektricheskie stantsii, 1994, no. 8, pp. 14-15.

10. Gorbachev S.V., Fot A.P., Shchipachev A.M., Lutfullin R.Y. Vliyanie poslesvarochnoy obrabotki na strukturnye osobennosti svarnykh soedineniy staley 20 i 30HGSA [Influence of post-welding treatment on structural features of welded joints of steels 20 and 30HGSA]. Vestnik Orenburgskogo gosudarstvennogo uni versiteta, 2015, no. 4 (179), pp. 159-164.

11. Popov A.B. Main factors causing damage to the high-temperature heating surfaces used in power-generating boilers. Thermal Engineering, 2011, vol. 58, no. 2, pp. 101-108.

12. Balakrishnan J., Vasileiou A.N., Francis J.A., Smith M.C., Roy M.J., Callaghan M.D., Irvine N.M. Residual stress distributions in arc, laser and electron-beam welds in $30 \mathrm{~mm}$ thick SA508 steel: a cross-process comparison. International Journal of Pressure Vessels and Piping, 2018, vol. 162, pp. 59-70.

13. Javadi Y., Smith M.C., Abburi Venkata K., Naveed N., Forsey A.N., Francis J.A., Ainsworth R.A., Truman C.E., Smith D.J., Hosseinzadeh F., Gungor S., Bouchard P.J., Dey H.C., Bhaduri A.K., Mahadevan S. Residual stress measurement round robin on an electron beam welded joint between austenitic stainless steel $316 \mathrm{~L}(\mathrm{~N})$ and ferritic steel P91. International Journal of Pressure Vessels and Piping, 2017, vol. 154, pp. 41-57.

14. RD 153-34.1-003-01. Svarka, termoobrabotka i kontrol trubnykh sistem kotlov i truboprovodov pri montazhe i remonte energeticheskogo oborudovaniya (RTM-1s) [Guidance 153-34.1-003-01. Welding, heat treatment and pipe systems control of boilers and pipelines during installation and repair of power equipment (RTM-1s)]. Moscow, PIO OBT Publ., 2002. 190 p.

15. SO 153-34.17.464-2003. Instruktsiya po prodleniyu sroka sluzhby truboprovodov II, III $i$ IV kategoriy [Guidance 153-34.17.464-2003. The instruction on extending the service life of II, III and IV categories pipelines]. Moscow, CPTI ORGRES Publ., 2004. 146 p.

16. Kogaev V.P. Raschety na prochnost pri napryazheniyakh, peremennykh vo vremeni [Calculations on the strength at stresses, changing in time]. Moscow, Mashinostroyenie Publ., 1993. 364 p.

17. Kharchenko S.A., Trunov N.B., Korotaev N.F., Lyakishev S.L. Measures for Ensuring Reliable Operation of the Welded Joint Connecting the Reactor Coolant Circuit's Header to the Shell of a Steam Generator Used at a VVER-1000 Reactor-Based Nuclear Power Station. Thermal Engineering, 2011, vol. 58, no. 3, pp. 208-214.

18. Dubov A.A. Problems in estimating the remaining life of aging equipment. Thermal Engineering, 2003, vol. 50, no. 11, pp. $935-938$.
19. Lyubimova L.L., Tashlykov A.A., Tabakaev R.B., Levin A.A., Popov A.Y. The effect of thermo-mechanical loading on fracturerelated parameters of austenitic steel. Engineering Failure Analysis, 2017, vol. 81, pp. 45-56.

20. Lyubimova L.L., Fisenko R.N., Tashlykov A.A., Tabakaev R.B. Changes in the State of Heat-Resistant Steel Induced by Repeated Hot Deformation. Metals and Materials International, 2018, vol. 24, no. 1, pp. 121-129.

21. Hsin Jen Hoh, John Hock Lye Pang, Kin Shun Tsang. Stress intensity factors for fatigue analysis of weld toe cracks in a girthwelded pipe. International Journal of Fatigue, 2016, vol. 87, pp. 279-287.

22. Kudryavtsev I.V., Naumchenkov N.E. Ustalost svarnykh konstruktsiy [Fatigue of welded structures]. Moscow, Mashinostroenie Publ., 1976. 270 p.

23. Adiban S.V., Ramu M. Study on the effect of weld defects on fatigue life of structures. Materials Today, 2018, vol. 5, no. 9, P. 1, pp. 17114-17124.

24. Trunov N.B., Davidenko S.E., Popadchuk V.S., Davidenko N.N., Berezanin A.A., Gutsev D.F., Lovchev V.N., Usanov D.A. Present state of the problem of managing the service life of steam generators used at nuclear power stations equipped with VVER reactors. Thermal Engineering, 2011, vol. 58, no. 3, pp. 184-189.

25. Hensel J., Nitschke-Pagel T., Tchoffo Ngoula D., Beier H.-Th., Tchuindjang D., Zerbst U. Welding residual stresses as needed for the prediction of fatigue crack propagation and fatigue strength. Engineering Fracture Mechanics, 2018, vol. 198, pp. 123-141.

26. Lyubimova L.L., Zavorin A.S., Tashlykov A.A., Tabakaev R.B. Sposob ustanovleniya sostoyaniya predrazrusheniya konstruktsionnogo izdeliya [The manufacturing method for a state of a structural work-piece pre-destruction]. Patent RF, No. 2613486, 2017.

27. Ekobori T. Fizika i mekhanika razrusheniya i prochnosti tverdykh tel [Physics and Mechanics of Physical Bodies Destruction and Strength]. Moscow, Metallurgiya Publ., 1971. 264 p.

28. Parton V.Z., Morozov E.M. Mekhanika uprugo-plasticheskogo razrusheniya [Mechanics of elastic-plastic failure]. Moscow, Nauka Publ., 1974. 416 p.

29. Serensen V. Soprotivlenie materialov ustalostnomu i khrupkomu razrusheniyu [Resistance of materials to fatigue and brittle fracture]. Moscow, Atomizdat Publ., 1975. 192 p.

30. Moroz L.S. Mekhanika i fizika deformatsiy i razrusheniya materialov [Mechanics and physics of materials deformation and fracture]. Leningrad, Mashinostroyeniye Publ., 1984. 224 p.

31. Friedel J., Gullity B.D., Crussard C. Study of the surface tension of a grain boundary in a metal as a function of the orientation of the two grains which the boundary separates. Acta Metallurgica, 1953, vol. 1, pp. 79-92.

32. Bugay N.V., Berezina T.G., Trunin I.I. Rabotosposobnost $i$ dolgovechnost metalla energeticheskogo oborudovaniya [Efficiency and durability of metal power equipment]. Moscow, Energoatomizdat Publ., 1994. 272 p.

Received: 24 September 2018.

Information about the authors

Alexander S. Zavorin, Dr. Sc., professor, National Research Tomsk Polytechnic University.

Lyudmila L. Lyubimova, Cand. Sc., associate professor, National Research Tomsk Polytechnic University.

Konstantin V. Buvakov, Cand. Sc., associate professor, National Research Tomsk Polytechnic University.

Aygul S. Kulesh, graduate student, National Research Tomsk Polytechnic University.

Alexander A. Tashlykov, Cand. Sc., associate professor, National Research Tomsk Polytechnic University.

Roman N. Kulesh, Cand. Sc., associate professor, National Research Tomsk Polytechnic University. 